\title{
Determination of Prospective Science Teachers' Level of Knowledge about Thermodynamics and Their Reasoning with Daily Life Examples
}

\author{
Eser Ültay ${ }^{1}$, Ümmü Gülsüm Durukan ${ }^{1}$, Neslihan Ültay ${ }^{1 *}$ \\ ${ }^{1}$ Department of Elementary Education, Faculty of Education, Giresun University, Giresun, Turkey \\ *Corresponding author: neslihan.ultay@giresun.edu.tr
}

\begin{abstract}
This study aimed to determine the relationships that prospective science teachers have established between thermodynamics and environmental problems. The study was conducted with the case study method. The sample consisted of 74 senior prospective science teachers selected by purposive sampling and studied in Science Teaching Department in the faculty of education of a state university in Turkey in the spring semester of the 2018-2019 academic year. The data collection tool consisted of two parts: The first part included four open-ended questions. It was the questionnaire in which the prospective science teachers were asked to explain the laws of thermodynamics. In the second part, eleven open-ended questions were expected to be explained the given environmental problems by the laws of thermodynamics. As a result of the study, prospective science teachers were found to have difficulty applying thermodynamics laws to daily events or environmental problems.
\end{abstract}

Keywords Environmental Problems, Laws of Thermodynamics, Prospective Science Teachers, Teaching Thermodynamics

\section{INTRODUCTION}

The industrialization movements that started in the $19^{\text {th }}$ century worldwide brought many environmental problems (EPs) such as global warming, air pollution, water pollution. Since these EPs are becoming a more significant concern, some precautions should be taken to prevent EPs. Undoubtedly, one of the most basic precautions is educating the individuals to eliminate EPs (Kahyaoğlu, 2009). For this purpose, in Turkey, environmental education starts from pre-school to university in formal education institutions in a considerable period. However, studies have shown that individuals still have not achieved the desired level of environmental awareness (Yücel \& Morgil, 1998). Although legal regulations have been prepared as a caution to prevent EPsaccording to Kahyaoğlu (2009), EPs are not only a problem that law can solve. It is essential to change the behaviors of the individual to avoid EPs. The attitude and value judgments of the individual are essential in changing behaviors. Therefore, individuals' positive attitudes towards the environment can effectively reduce people's role in the occurrence of EPs. On the other hand, energy issues in nature are factors triggering EPs (Kırtak, 2010).

Since all events in nature can be explained by energy transfer or transformation (Mansson \& McGlade, 1993), it is clear from this perspective that EPs will never end completely. Thermodynamics, besides, is an interdisciplinary subject of physics, chemistry, and biological sciences since it is an area related to heat exchange and energy. There are very few educational studies in which the relationship between thermodynamics and the environment is established. Therefore, this study, which approaches thermodynamic and environmental problems from a different perspective, is considered the basis for further research. Literature Review

The studies on thermodynamics have revealed that a significant part of these studies is conducted for concept teaching. In these studies, it is seen that in addition to collecting qualitative and quantitative data, applications are

Received: 20 November 2020

Revised: 28 February 2021

Published: 06 July 2021 
made to identify misconceptions and to eliminate these misconceptions (Bain, Moon, Mack, \& Towns, 2014; Harrison, Grayson, \& Treagust, 1999).

Due to the confusion of heat and energy concepts, students often have difficulty learning thermodynamics (Cotignola, Bordogna, Punte, \& Cappannini, 2002; Harrison et al., 1999), and it is also inevitable that they have misconceptions. Unfortunately, however, the number of studies on thermodynamics in education is limited (Baran \& Sözbilir, 2018; Tanel, 2006; Tatar \& Oktay, 2011).

Sreenivasulu and Subramaniam (2013) conducted their studies on thermodynamics with 106 university graduates of the chemistry department. The study aimed to find out the understanding of thermodynamics by graduate students through a four-stage test. The results of this study reiterated that thermodynamics was a science full of conceptual difficulties and alternative understandings. Loverude, Kautz, and Heron (2002) conducted a study with a group of physics students from the first and secondgrade students of the university and tried to reveal the students' understanding of the 1.law of thermodynamics (1.LoTD). They found that students frequently failed to differentiate the concepts of heat, temperature, work, and internal energy. Thomas and Schwenz (1998) found many misconceptions about thermodynamics in their studies with $4^{\text {th }}$-grade chemistry students. Klimenko (2012), in his study with engineering students, found that the 1.LoTD was not difficult for the students, but they had difficulty in understanding the concepts of entropy with the 2.LoTD and 3.LoTD. Similarly, Sözbilir (2004) found that students had misconceptions about thermodynamics and entropy.

The concept of entropy is seen to be the subject of joint studies on thermodynamics and the environment. Many EPs in nature can be explained by the increase of entropy (Kırtak, 2010) because all the changes in our environment are irreversible (Smith, 2001). For example, the underground energy resources are an example of a high entropy situation, while burning fossil energy sources and giving $\mathrm{CO} 2$ to the atmosphere is a low entropy situation. Sözbilir and Bennett (2007), in their study of university students taking the course of physical chemistry, can explain the concept of entropy with a disorder. However, they found that students often had the wrong information. They saw the concept of entropy as equivalent to confusion. Ribeiro (1992) also reached similar conclusions and found that entropy was equivalent to chaos and disorder.

One of the studies in which thermodynamics is related to the environment or EPs belongs to Tokuya, Yamamoto, and Takashi (2004). They investigated that how high school and university students associated environmental issues with physics. As a result of the study, most university students did not remember the LoTD existing in environmental issues, and they were not aware that high school and university students could have explained many phenomena in nature with the laws of physics they had learned before. Öztaş (2005), on the other hand, applied an open-ended questionnaire to 135 students in the ninth grade to investigate the extent to which students could adapt their knowledge about LoTD to ecological systems. At the end of the study, it was seen that students could not have established a relationship between the conservation of matter and matter cycle and energy conversion. He also found that the students did not consider LoTD and could not have applied LoTD to ecological events. Kırtak-Ad and Demirci (2012) investigated the level of the relationship between LoTD and EPs of 245 physics, chemistry, and prospective biology teachers in their studies. As a result of the study, prospective teachers could not have established a relationship between thermodynamics and EPs in terms of energy pollution (nuclear power plants, radioactive material residues, environmental pollution caused by nuclear weapons producing factories are defined as energy pollution) and thermal pollution (thermal pollution is the deterioration of the quality of the water by any operation that changes the temperature of the environmental water). They were found to have difficulty in applying the LoTD to EPs.

It is crucial to identify misconceptions for better teaching, as well as how these concepts are applied to everyday events because the actual learning begins with the adaptation of what students have learned to different events or with explaining the daily events by the information they have learned (Coştu, Ünal, \& Ayas, 2007). The connection of LoTD with the environment is also essential in this respect. As mentioned above, unfortunately, there are very few educational studies in which thermodynamics and environment are associated. Therefore, this study, based on thermodynamics and EPs' association, is expected to shed light on the following research. This study aims to determine the relationship between EPs and LoTD of the prospective science teachers (PSTs) from this point of view. For this purpose, the following research problems were sought:

What is the level of knowledge of the prospective science teachers about the laws of thermodynamics?

How do the prospective science teachers make environmental reasoning problems with laws of thermodynamics?

\section{METHOD}

\subsection{Research Design and Sample}

This study was carried out with the case study method, one of the qualitative research approaches. A case study is a research method that provides a portrait of what this phenomenon is like (Cohen, Manion, \& Morrison, 2007; Yin, 2003), conducting an in-depth study and comparing the data according to particular circumstances (Patton, 1990). 
The sample selected by using purposive sampling and consisted of 74 senior prospective science teachers (PSTs) (48 females, 26 males, and aged 23-24) in the Science Teaching Department in a faculty of education of a state university in Turkey in the spring semester of 2018-2019 academic year. PSTs gained information about LoTD in the "Physics-III" course (The topics: Thermodynamics: Heat and temperature, Thermal properties of matter (Specific heat, thermal conductivity, thermal expansion), Thermodynamic laws, reversible and irreversible events, efficiency and entropy), and environmental issues in "Environmental Science (The topics: Water, Soil, Air, Radioactive pollution and other sources of pollution)" and "Special Topics in Chemistry (The topics: Air pollution, Greenhouse gases, and their importance, Water pollution, Environment, and environmental problems in the light of chemistry, Chemical pollution, Nuclear Energy)" courses at different semesters.

\subsection{Data Collection Tools}

The questionnaire used as a data collection tool can be examined in two parts. These parts are introduced below:

In the first part of the questionnaire, there are four open-ended questions in which PSTs are asked to explain the meaning of the LoTD.

In the second part of the questionnaire, eleven openended questions are expected to explain by the LoTD of the given EPs.

In the questionnaire development phase, the opinions of three experts who completed their Ph.D. in physics and chemistry education and science education were taken.

\subsection{Data Collection Process}

The data collection process took two weeks. There was no time limitation while the PSTs completed the questionnaire, and the PSTs were released on time. In the first week, the first part of the questionnaire tool was applied to the PSTs for approximately one hour. The second week took 60-70 minutes for the PSTs to complete the second part of the questionnaire.

\subsection{Data Analysis}

In the first part of the questionnaire, the data obtained from open-ended questions about LoTD were analyzed

Table 1 Some information about the experts whose opinions were included in the study

\begin{tabular}{lll}
\hline Science Experts & & \\
\hline Title & Field of Expertise & Experience \\
\hline Associate Professor & Physical Chemistry & 25 years \\
Associate Professor & Biochemistry & 15 years \\
Associate Professor & Solid State Physics & 14 years \\
Associate Professor & Atom and Molecule & 14 years \\
Associate Professor & Atom and Molecule & 9 years \\
PhD & Solid State Physics & 10 years \\
\hline Language Experts & & \\
\hline Title & Field of Expertise & Experience \\
\hline $\mathrm{PhD}$ & Language and & 18 years \\
& Literature & \\
\hline
\end{tabular}

through content analysis. For the second part of the questionnaire, an answer key was created by asking six physics and chemistry experts to answer the questions. Information about the experts whose opinions were included in the study is presented in Table 1.

The answers of the PSTs were analyzed with understanding levels in Table 2 that Abraham, Williamson, and Westbrook (1994) put forward and these understanding levels are used in some recent studies such as Çalık and Cobern (2017) and Yaman, Ayas, and Çalık (2019). Therefore, the understanding levels used in these studies were slightly arranged in this study to avoid confusion. In addition, a limited understanding level (LU) was added. Finally, the answer key prepared based on the experts' opinions and the understanding levels shown in Table 2 was used to analyze the data.

While quoting the statements of the PSTs, they were coded as PST1, PST2, PST3,..., PST74. If the PSTs answered sequentially, the coding was shortened by placing "-" between the numbers in the code. For example, instead of showing "PST1, 2, 3, 4, 5", it is shown as "PST1-5").

\subsection{Validity and Reliability of the Study}

Before the data collection process, the researchers informed the PSTs that "these activities and data would not constitute any assessment for your courses," "applications and data would be used for research purposes only," and "no information would be shared with study readers except for some demographic information." Besides, PSTs were informed about the content of the study. Furthermore, all ethical responsibilities were considered, and informed consent was taken from PSTs. The purpose of this information is to increase the credibility of the study by enabling PSTs to respond comfortably and sincerely during the data collection process.

In order to increase the study's credibility and consistency, the necessary reductions (unnecessary words were omitted) were made three different times by the researchers, and the critical answers were determined. Then, some codes were created according to the PSTs' answers. Finally, these codes were divided into appropriate themes/categories. Expert opinions ensured the validity and reliability of these stages.

The second part of the data collection tool was evaluated according to the understanding levels prepared by the researchers. However, it was considered that this would not have brought very objective and accurate results to ensure the reliability of the comparative agreement between the two evaluators. Therefore, a different field education expert was asked to evaluate the data. The expert also grouped the data obtained from the first part of the data collection tools, and he placed the answers under the appropriate themes. Afterward, the total agreement with the researchers' answers was calculated by using the IBM SPSS v22 package program by calculating the Cohen's Kappa value between the two readers. The calculated 
Table 2 Understanding levels and explanations of the levels

\begin{tabular}{|c|c|c|c|}
\hline $\begin{array}{l}\text { Understanding } \\
\text { levels }\end{array}$ & $\begin{array}{l}\text { Abbre } \\
\text { viation }\end{array}$ & $\begin{array}{l}\text { Explanations of the } \\
\text { understanding levels }\end{array}$ & $\begin{array}{l}\text { Example explanations of } 2 \text { nd question for the } \\
\text { understanding levels } \\
\text { (Q2: Is it possible for a gasoline automobile's engine } \\
\text { (internal combustion engines) to operate at } 100 \% \\
\text { energy efficiency? Explain the reasons.) }\end{array}$ \\
\hline $\begin{array}{l}\text { No } \\
\text { understanding }\end{array}$ & {$[\mathrm{NU}]$} & $\begin{array}{l}\text { Unclear, } \\
\text { incomprehensible } \\
\text { answers and the answers } \\
\text { are left blank. }\end{array}$ & Exhaust fumes cause air pollution (PST20) \\
\hline $\begin{array}{l}\text { Misunderstandin } \\
\mathrm{g}\end{array}$ & [MU] & $\begin{array}{l}\text { Answers containing } \\
\text { misconceptions and/or } \\
\text { incorrect information. }\end{array}$ & $\begin{array}{l}\text { If we call the gas-powered car } 80 \% \text { efficient, the gasoline } \\
\text { could be } 100 \% \text { (PST14) }\end{array}$ \\
\hline $\begin{array}{l}\text { Partial } \\
\text { understanding }\end{array}$ & [PU] & $\begin{array}{l}\text { Answers containing } \\
\text { correct information at } \\
\text { the basic level (short } \\
\text { answers, giving examples, } \\
\text { etc.). }\end{array}$ & $\begin{array}{l}\text { It is not possible normally. But it is possible if they can } \\
\text { remove the friction force (PST10) }\end{array}$ \\
\hline $\begin{array}{l}\text { Limited } \\
\text { understanding }\end{array}$ & {$[\mathrm{LU}]$} & $\begin{array}{l}\text { Answers containing no } \\
\text { misconceptions and } \\
\text { incorrect information, } \\
\text { answers with acceptable } \\
\text { information. }\end{array}$ & $\begin{array}{l}\text { Not possible because losses will occur during energy } \\
\text { conversions (PST } 52 \text { ) }\end{array}$ \\
\hline $\begin{array}{l}\text { Sound } \\
\text { understanding }\end{array}$ & {$[\mathrm{SU}]$} & $\begin{array}{l}\text { Complete and accurate } \\
\text { answers. }\end{array}$ & $\begin{array}{l}\text { It cannot work in } 100 \% \text { efficiency. Heat will be released and } \\
\text { entropy will increase. It concerns the second LoTD. In } \\
\text { addition, energy cannot be created or destroyed, there is only } \\
\text { conversion of energy (PST25) }\end{array}$ \\
\hline
\end{tabular}

Cohen's Kappa $(x)$ was found to be 0.915 , and it was found that almost perfect agreement was achieved according to Landis and Koch's (1977) classifications. After this stage, the researchers evaluated the second part of the form.

Besides, the data collection process was carried out in the classroom where an environment researchers were accustomed to, and thus, it had been tried to increase the study's credibility. Transferability is another criterion used in qualitative research instead of generalization (Miles \& Huberman, 1994). In qualitative researches, research results can be transferred to similar situations rather than the generalization of them (Yıldırım \& Şimşek, 2011). In this study, to increase the transferability, the data obtained during the research process are presented to the reader in the findings section without commenting on them and preserving the data's nature and organized under the themes and categories where necessary. In this way, the reader will be able to reach conclusions about the research situation more clearly and get the opportunity to transfer them to other research situations. The results of the research should be supported by the data (Miles \& Huberman, 1994). This is an indicator of the verifiability of the data. In this researc $h$, the direct statements of the participants were given for the verification of the data.

Another critical point in ensuring the validity and reliability of the study is the position of the researchers. Researchers are faculty members that the PSTs see for four years and conduct the PSTs' lessons from time to time. This situation provided the opportunity to overcome the lack of long-term participation in the study.

As a final point, the implementation was carried out in Turkish because the education language is Turkish. So first, the questions were asked in Turkish, and then they were all translated into English. An English language lecturer had controlled the translations.

\section{RESULTS}

The data shown in the findings section are grouped under two headings: (1) The data relating to the knowledge levels of the PSTs about the LoTD are presented under the first heading. (2) The findings obtained from the explanations made by the PSTs by reasoning EPs with LoTD are presented under the second heading.

\subsection{Findings from the Analysis of Data Related to the Knowledge Levels of the PSTs about LoTD}

The findings of the data that the PSTs explained their LoTD are presented in the following tables. Tables 3-6 show the coded statements, and some PSTs' statements (the most remarkable ones) were given the related table afterward. Table 3 shows the explanations of the PSTs about the zeroth LoTD. The first question was: How do you explain the zeroth law of thermodynamics?

According to Table 3 , most of the PSTs explained the zeroth LoTD as "If $\mathrm{A}=\mathrm{B}$ and $\mathrm{A}=\mathrm{C}$, then $\mathrm{B}=\mathrm{C}$ " and 
"The substances are at equal temperature. Therefore, there is no heat exchange." The explanations of the PSTs regarding the first LoTD are given in Table 4. The second question was: How do you explain the first law of thermodynamics?

In Table 4, the PSTs explained the first LoTD to a large extent $(f=51)$ in such a way that "Energy cannot be created or destroyed. Only the transformation takes place". Table 5 shows the explanations of the PSTs about the second LoTD. The third question was: How do you explain the second law of thermodynamics?

The PSTs tried to explain the second LoTD with "Heat is converted to work, and work is converted to heat," "Heat transfer is from hot to cold," and "No system efficiency can be greater than 1, there are losses." The explanations of the PSTs about the third LoTD are given in Table 6. The fourth question was: How do you explain the third law of thermodynamics?

Table 3 Explanations of the PSTs about the Zeroth LoTD

\begin{tabular}{|c|c|c|}
\hline Answers & Prospective Science Teacher & $f$ \\
\hline $\begin{array}{l}\text { All three materials in the same environment have the same } \\
\text { heat energy, thermal equilibrium. If } \mathrm{A}=\mathrm{B} \text { and } \mathrm{A}=\mathrm{C} \text { then } \mathrm{B} \\
=\mathrm{C} \text {. }\end{array}$ & $\begin{array}{l}\text { PST5, 10-11, 15-17, 23, 25-26, 29, 31, 36, } \\
40,44,48,52,56,67-72\end{array}$ & 23 \\
\hline $\begin{array}{l}\text { It is that the substances are at equal temperature. This is the } \\
\text { absence of heat exchange. }\end{array}$ & $\begin{array}{l}\text { PST24, 27, 37, 41, 43, 47, 50, 54-55, 57, } \\
60-61\end{array}$ & 12 \\
\hline $\begin{array}{l}\text { Energy cannot be created or destroyed. Only the } \\
\text { transformation takes place. }\end{array}$ & PST4, $7,19,39,42,74$ & 6 \\
\hline The energy of a working system is never zero. & PST45, 53, 62 & 3 \\
\hline It is the balance of temperature. & PST58, 63 & 2 \\
\hline It is the basic balance of systems. & PST51, 59 & 2 \\
\hline It is the conservation of heat. & PST8, 22 & 2 \\
\hline $\begin{array}{l}\text { Between two objects of different temperatures, heat energy is } \\
\text { transferred from the hot object to the cold one. }\end{array}$ & PST35 & 1 \\
\hline Chemical and physical events. & PST65 & 1 \\
\hline Temperature protection. & PST49 & 1 \\
\hline The absence of heat exchange between the same objects. & PST66 & 1 \\
\hline The temperature is below zero. & PST20 & 1 \\
\hline No description. & $\begin{array}{l}\text { PST1-3, 6, 9, 12-14, 18, 21, 28, 30, 32-34, } \\
38,46,64,73\end{array}$ & 19 \\
\hline
\end{tabular}

Table 4 Explanations of the PSTs about the First LoTD

\begin{tabular}{lll}
\hline Answers & $\begin{array}{l}\text { Prospective Science } \\
\text { Teacher }\end{array}$ & $f$ \\
\hline Energy cannot be created or destroyed. Only the transformation takes place. & $\begin{array}{l}\text { PST1, 4-5, 9-19, 21, 23-30, 32- } \\
\text { 33, 35-36, 41, 43, 45, 47, 49- }\end{array}$ \\
& $50,52-58,60-61,64-65,67-69$, \\
& $71-74$ & 3 \\
It is the conservation of energy. & PST48, 51, 66 & 2 \\
Heat transfer between materials with different temperatures is heat exchange. & PST46, 62 \\
The change in the system's internal energy is the difference between the & PST44, 70 \\
amount of heat given to that system and the work it applies to its & & 2 \\
environment. & & 1 \\
Express heat movements. & PST20 \\
Heat and temperature progress from high to low. & PST22 \\
It is about heat and temperature. For example, the ozone layer is perforated. & PST34 & 1 \\
No sudden change in heat and temperature. & PST8 \\
The internal energy of a closed system is constant. & PST39 \\
The relationship between heat and work. & PST63 \\
Total amount of matter and energy conservation. & PST59 \\
No description. & PST2-3, 6, 7, 31, 37, 38, 40, 42 & 9 \\
\hline
\end{tabular}


Finally, the PSTs tried to explain the third LoTD with the words, "When the absolute zero temperature is reached, entropy remains constant or approaches constant, and particles come to a halt" and "A substance cannot be cooled to the absolute temperature."

\subsection{The Findings Obtained from the Analyses of the PSTs' Explanations by Reasoning EPs with LoTD}

Table 7 shows the frequency distributions in understanding explanations made to the questions that the PSTs are asked to make reasoning EPs with the LoTD.

PSTs are expected to relate the situation contained in the first question with the first LoTD. Since car engines do not work at 100\% efficiency, they provide nature with unused energy in the form of heat. It causes the greenhouse effect and exhaust gases. Nevertheless, these gases cause air pollution and thus water and soil pollution. They also cause sound pollution due to engine and horn sounds. The first question was answered as "Exhaust gas pollutes the environment, i.e., air" by PST1, and his answer was placed under the PU category. PST11 said that "Exhaust gases cause air pollution. Besides, this pollution will cause pollution of rainwater and soil," and her answer was placed in the LU category.

PST10 answered the second question as "It is not possible normally. But it is possible if they can remove the friction force," and this answer was placed in the PU

Table 5

Explanations of the PSTs about the Second LoTD

\begin{tabular}{llc}
\hline Answers & $\begin{array}{l}\text { Prospective Science } \\
\text { Teacher }\end{array}$ & $f$ \\
\hline Heat is converted to work, and work is converted to heat. & $\begin{array}{l}\text { PST19, 27, 29, 44, 50-52, 54, } \\
\text { 56, 59-60, 64, 69, 71 }\end{array}$ & 14 \\
& PST5, 11, 13, 25-26, 57, 62-63, & 9 \\
Heat transfer is from hot to cold. & 70 & PST4, 41, 43, 45, 49, 53, 66 \\
& PST35, 68, 72 & 3 \\
No system efficiency can be greater than 1, and there are losses. & PST14 & 1 \\
It is about the transformation of energy. & PST39 & 1 \\
As a result of the heating process, the ambient temperature does not change. & 1 \\
As entropy increases, light slows down and then disappears. & PST22 & 1 \\
Energy cannot be created or destroyed. Only the transformation takes place. & PST47 & 1 \\
Everything goes in the direction of increasing entropy. & PST24 & 1 \\
Heat is converted to light, and light is converted to heat. & PST40 & 1 \\
It is the acceleration of the object which is released from high downwards. & PST33 & 1 \\
It relates to inertia and the heat-receiving material expands. & PST20 \\
The heat given is equal to the heat taken. & PST12 & 1 \\
The received temperature is equal to the given temperature. & PST32 & 1 \\
The relationship between heat balance and conservation. & PST65 \\
They are spontaneous reactions with low threshold energy in the universe. & PST42 \\
When enthalpy increases, the heat slows down and its shape disappears. & PST1-3, 6, 7-10, 15-18, 21, 23, & 29 \\
No description. & $28,30-31,34,36-38,46,48$, \\
\end{tabular}

Table 6 Explanations of the PSTs about the Third LoTD

\begin{tabular}{llc}
\hline \multicolumn{1}{c}{ Answers } & \multicolumn{1}{c}{ Prospective Science Teacher } & $f$ \\
\hline When the absolute temperature is reached, the entropy remains & PST15, 26-27, 29, 41, 43-45, 47-48, 50- & 21 \\
constant or approaches the constant and the particles come to a halt. & $52,54,56-57,59,64,66,69-72$ & \\
A substance cannot be cooled to the absolute temperature. & PST4, 24, 39, 42, 49, 53, 55, 61, 63 & 9 \\
Heat exchange. & PST12, 34 & 2 \\
Boiling takes place at a certain temperature. & PST14 & 1 \\
Each substance has internal energy and as temperature increases then & PST62 & 1 \\
motion increases. & PST35 & 1 \\
Heat transfer is from hot to cold. & PST65 & 1 \\
It is the expansion of the universe. & PST74 & 1 \\
No colder environment than absolute temperature. & PST22 & 1 \\
Temperature is the sum of the heat. & PST1-3, 5-9, 13, 16-21, 23, 25, 28, 30- & 32 \\
No description. & $33,36-38,40,46,58,60,67-68,73$ & \\
\hline
\end{tabular}


Table 7 The frequencies of PSTs' explanations by associating EPs with LoTD

\begin{tabular}{|c|c|c|c|c|c|}
\hline Questions & $\begin{array}{l}\text { SU } \\
(f)\end{array}$ & $\begin{array}{l}\text { LU } \\
(f)\end{array}$ & $\begin{array}{l}\text { PU } \\
(f)\end{array}$ & $\begin{array}{l}\text { MU } \\
(f)\end{array}$ & $\begin{array}{l}\text { NU } \\
(f)\end{array}$ \\
\hline $\begin{array}{l}\text { Does a car bring an EP while running? Please explain the } \\
\text { reasons. }\end{array}$ & 0 & 4 & 68 & 1 & 1 \\
\hline $\begin{array}{l}\text { Is it possible for a gasoline automobile's engine (internal } \\
\text { combustion engines) to operate at } 100 \% \text { energy efficiency? } \\
\text { Explain the reasons. }\end{array}$ & 1 & 6 & 48 & 13 & 6 \\
\hline $\begin{array}{l}\text { Does double-glazed windows harm the environment? Explain } \\
\text { the reasons. }\end{array}$ & 0 & 4 & 51 & 11 & 8 \\
\hline $\begin{array}{l}\text { Does air conditioners harm the environment? Explain the } \\
\text { reasons. }\end{array}$ & 0 & 5 & 53 & 8 & 8 \\
\hline $\begin{array}{l}\text { How can you relate the transition from light bulb to LED } \\
\text { lighting technology with environmental issues, considering the } \\
\text { LoTD? Please explain the reasons. }\end{array}$ & 0 & 1 & 17 & 22 & 34 \\
\hline $\begin{array}{l}\text { How does global warming affect the entropy of our world? } \\
\text { Please explain the reasons. }\end{array}$ & 0 & 8 & 46 & 14 & 6 \\
\hline $\begin{array}{l}\text { Does urbanization, which intensifies along the rivers, affect } \\
\text { entropy? Please explain the reasons. }\end{array}$ & 2 & 10 & 46 & 9 & 7 \\
\hline $\begin{array}{l}\text { How is the temperature of a lake measured with a mercury } \\
\text { thermometer? Does it matter for the measurement if the water in } \\
\text { the lake dirty or clean? Please explain the reasons. }\end{array}$ & 0 & 2 & 20 & 28 & 24 \\
\hline $\begin{array}{l}\text { How do you relate the energy conversion in nuclear power plants } \\
\text { to the LoTD? How do these transformations affect the } \\
\text { environment? Please explain the reasons. }\end{array}$ & 0 & 4 & 56 & 1 & 13 \\
\hline $\begin{array}{l}\text { Would it be effective to open the door of a working refrigerator } \\
\text { to cool the kitchen on a hot summer day or open the door of a } \\
\text { working oven to heat it on a cold winter day? Please explain the } \\
\text { reasons. }\end{array}$ & 0 & 1 & 7 & 58 & 8 \\
\hline $\begin{array}{l}\text { How does the thermometer with the digital display measure the } \\
\text { temperature in clean and dirty weather in the city center? Does } \\
\text { clean or dirty air affect the measurement? Please explain the } \\
\text { reasons. }\end{array}$ & 0 & 1 & 37 & 25 & 11 \\
\hline $\begin{array}{l}f_{\text {total }} \\
(\%)\end{array}$ & $\begin{array}{l}3 \\
(0.37 \%) \\
\end{array}$ & $\begin{array}{l}46 \\
(5.65 \%) \\
\end{array}$ & $\begin{array}{l}449 \\
(55.16 \%)\end{array}$ & $\begin{array}{l}190 \\
(23.34 \%)\end{array}$ & $\begin{array}{l}126 \\
\left(15.48^{\circ}\right. \\
\end{array}$ \\
\hline
\end{tabular}

category. PST25 answered the same question as "It cannot work in 100\% efficiency. Heat will be released, and entropy will increase. It concerns the second LoTD. Besides, energy cannot be created or destroyed. There is the only conversion of energy," and his answer was placed in the SU category.

The situation given in the third question can be associated with the first LoTD by PSTs. It is environmentally friendly because entropy increases less, chemicals used in wooden windows are not used, and good heat and sound insulation. Therefore, the third question was answered as "No harm. Because double-glazed windows provide heat and sound insulation and reduce the factors that may cause harm to the environment." Their answers were placed in the LU category. Besides, PST3 and 69 said that "No harm, it provides heat insulation," and their answers were placed under the PU category.

Regarding the fourth question, although air conditioners save energy, air conditioners increase the system's entropy as in all heat treatments following the second LoTD. Also, air conditioning gas (freon) causes severe damage to the ozone layer. PST3 answered the fourth question as "Yes. The sound coming from the engine pollutes the environment," and PST4 "Yes. Because it has serious damages to the ozone layer." These answers were both placed under the PU category. PST16 and 32 answered as "Air conditioners work on the principle of energy conversion. According to the second LoTD, they do not work in 100\% efficiency, and there is an increase in entropy and harm to the environment." Their answers were placed in the LU category.

PSTs are expected to relate the situation in this question to the second LoTD. According to this law, the entropy of the system increases in all energy-consuming processes in the universe. Considering that LED lighting is more efficient, longer-lasting, and uses less energy than bulbs, it is a more sensitive environment. The fifth question was answered by PST25 as "There is more energy loss in bulbs 
than LED lighting technologies. According to the first law of thermodynamics, some of the energy is converted to heat." in the PU category.

According to the entropy law, all beings in the universe are doomed to decay. This is an inevitable transformation. Global warming also shortens this conversion time and contributes to the disorganization of the system. Therefore, the situation in this question is expected to be associated with the second LoTD. The sixth question was answered by PST9 and 11 as "Entropy means disorder or imbalance in the system. Global warming is also triggering this disorder." Therefore, their answers were placed in the LU category. PST21 answered, "It increases the entropy, the irregularity occurs," and responded in the PU category.

PSTs are expected to associate the situation contained in the problem with the second and third LoTD. In this problem, the urbanization concentrated on the edges of the stream increases the system's entropy. The seventh question was answered by PST1 in such a way that "The balance of water is disturbed wastes settling on the rivers, and it causes deterioration and increase of entropy." This answer was placed in the SU category. For the same question, PST2 said that "Urbanization results in irregularity and entropy increases," and her response was appropriate for the LU category. PST8 and 9 stated that in PU category in such a way that "Yes it does because imbalance occurs in some places due to dense settlement, and some places less dense settlement."

For the eighth question, it can be said that the most accurate measurement is taken at the same time by taking the average of a large number of measurements taken from different points of the lake. The temperature of the dirty lake water will be measured more since it will absorb the light more. Therefore, PSTs are expected to relate to the zeroth LoTD in this question. PST15 answered the eighth question following the LU category in such a way that "Water being dirty or clean will affect the temperature because it can hold the sun's rays." In addition, PST33 is in the PU category with the answer "Measurement cannot be made with a mercury thermometer, but the more polluted the water, the warmer it is."

It is thought that PSTs may associate the case of the ninth question with all LoTD because there is an irreversible process between heat and energy in this question. However, for this question, PSTs were mainly expected to establish a relationship with the second LoTD due to the change of energy. However, this system does not work with $100 \%$ efficiency, and a large amount of coolant is used in these plants. These fluids also increase the temperature of the rivers and lakes in that region. Therefore, it causes an increase in entropy. PST9 answered the ninth question as, "The first and third laws of thermodynamics are concerned. There is energy conversion. It positively affects being an effective energy source and adversely affects the environment due to radioactive pollution." in the LU category. PST14 said that "Energy cannot be created or destroyed. There is no energy conversion" in the MU category.

These devices (refrigerator and oven) transfer heat. In other words, it displaces cold air with hot air. While doing this work, the electric motor is used, and this motor will heat the environment while running. So both devices act like electric heaters, so both heat the environment. Therefore, PSTs are expected to relate the situation to the second LoTD. PST38 responded to the tenth question: "The refrigerator will work harder to cool the environment and emit heat. The opposite goes for the oven. Total temperature does not change." This response was placed in the LU category.

The situation given in this question is expected to relate to the zeroth LoTD by PSTs. Digital display thermometers measure using electronic circuits. The dirty air temperature is measured more than it should since the dirty substances in the air will absorb the light rays more. PST4 answered the eleventh question following the PU category with the words "yes it affects, the temperature is measured more accurately if the air is clean." PST57 said that" It affects temperature. The polluted air will shed the sunlight." This answer was placed in the LU category.

\section{DISCUSSION}

In parallel with the findings section, the discussion section is presented under two headings: (1) Discussion on the knowledge levels of the PSTs about LoTD is presented under the first title. (2) The discussion of the PSTs' explanations made by reasoning EPs with LoTD is presented under the second heading.

\subsection{Discussion on the Knowledge Levels of the PSTs about LoTD}

When the explanations of the PSTs regarding the zeroth LoTD are examined, it is seen that most of the PSTs' explanations are related to thermal equilibrium and heat exchange. Similarly, Başer and Çataloğlu (2005) also found that students had a misconception that "when two liquids are mixed, the temperature of the new mixture is the sum of the temperatures of both liquids."

When the PSTs' explanations regarding the first LoTD are examined, it is seen that the explanations focus on the "energy cannot be created or cannot be destroyed, and it is the transformation of energy." Yeo and Zandik (2001) found that students had difficulty understanding the first LoTD and applying this law in problem-solving. Loverude et al. (2002) and Meltzer (2007) have reported that university students emerge with significant learning difficulties related to fundamental concepts in thermodynamics, such as heat, work, cyclic processes, and the first LoTD. In contrast, Klimenko (2012) found that students understand the first LoTD but cannot comprehend entropy and the second LoTD and third LoTD. In this study, when the explanations of the PSTs 
regarding the second LoTD are examined, the explanations of the PSTs are generally grouped under three statements: Heat and work transformation, heat transfer, and efficiency. Loverude et al. (2002) and Christensen, Meltzer, and Ogilvie (2009) stated that students do not understand the second LoTD and entropy. In this study, when the explanations of the PSTs regarding the third LoTD are examined, the statements of the PSTs are usually related to absolute temperature. A significant part of the absolute temperature explanation is that the entropy will remain constant when the absolute temperature is reached, and the particles will come to a halt. Sözbilir (2002) and Haglund, Andersson, and Elmgren (2016) revealed that students could not understand the concept of entropy, the central concept of thermodynamics. Sreenivasulu and Subramaniam's (2013) study determined that students have alternative concepts related to enthalpy, entropy concepts, energy transfer, and third LoTD issues.

It was determined that a significant part of the PSTs could not explain the zeroth LoTD, second LoTD, and third LoTD. To overcome these shortcomings in the literature, learning environments using different teaching approaches and methods have been developed, and the effectiveness of these environments has been tested. They found that context-based learning and problem-based learning (Baran \& Sözbilir, 2018) helped teach thermodynamics subjects and concepts. Tanel (2006) designed a cooperative learning environment to complement these students' deficiencies and revealed that this learning environment increased academic achievement. However, Kulkarni and Tambade (2013) found that computer-assisted instruction effectively determines students' understanding of LoTD.

\subsection{Discussion of the PSTs' Explanations by Reasoning EPs with LoTD}

When the explanations made by the PSTs concerning EPs with LoTD are examined, it is seen that the PSTs' answers were concentrated in the PU category (Table 7). In the explanations regarding the EPs in the first, second, fourth, and eleventh questions, some of the PSTs reasoned the situations related to the given EPs with entropy. Some of them are related to air pollution. For example, when the opinions of the PSTs about air conditioners were taken in the fourth question, it was determined that many of the PSTs stated that air conditioners were harmful to the ozone layer. However, a small number of these PSTs could reason with the second LoTD considering the working principle of air conditioners and indicated an increase in entropy. However, it was seen that the PSTs could have reasoned air pollution with LoTD; Kirtak (2010) revealed that the prospective teachers stated that LoTD could not explain air pollution in her study. In the second, third, fifth, and tenth questions, the EPs' explanations were focused on the concept of entropy and reasoned with the change of entropy. In the case of the third question, it was seen that most of the PSTs said that double-glazed windows were beneficial to the environment because they prevent heat transfer and provide heat insulation. The answers to this question were also associated with recycling. However, it is noteworthy that the PSTs could not relate the first LoTD to this situation even though they referred to heat transfer for the situation in this question. The answers primarily explained the situation related to the ninth question's energy transformations at the "partially correct" comprehension level. Some of the PSTs could have been reasoned with the first LoTD and third LoTD. However, it has been revealed in the literature that energy transformations cannot be understood by the participants at different levels (Pidgeon \& Demski, 2012).

In this study, for the eighth question, which was asked if a thermometer measured a lake's temperature, it was determined that the PSTs explained the case by thermal equilibrium or heat exchange. Similarly, Kirtak (2010) found that prospective teachers explained the situation related to the zeroth LoTD by thermal equilibrium. In the tenth question, almost all answers about using the refrigerator to cool the environment or to heat the environment with the oven were in the misunderstanding category. Since the environment in which the refrigerator/oven is not isolated, these devices should be operated up to the equilibrium temperature in open systems. This is indicated by the experts involved in this study, which means that too much energy usage and entropy increase. In the study of Cochran and Heron (2006), it was stated that university students could not apply the second LoTD to systems such as heat machines and refrigerators, and often explained the first LoTD instead of the second LoTD. The EPs in the seventh and eighth questions can be related to water. It often explained the seventh question, the effect of urbanization on the riverside entropy. The PSTs stated that with urbanization, water balance will be disrupted/water will be polluted, and entropy will increase. The PSTs' knowledge of water pollution may not be sufficient to interpret the EP by reasoning it with the LoTD. Covitt, Gunckel, and Anderson (2009) stated that environmental literacy related to water is related to water and the human environment's natural structure. For this purpose, students must know the nature of water and its ability to be found in nature in different forms. In this study, it is seen that water pollution is partly related to LoTD.

Contrary to this situation, Kurtak (2010) found that prospective teachers cannot explain water pollution by LoTD. In the sixth question, it was seen that the PSTs' answers were placed in the category of partial understanding about the situation of global warming affecting the entropy of the world, and they stated that global warming would disrupt the balance and increase the entropy. Kurtak (2010) found similar expressions in the 
study, and it was determined that the prospective teachers explained global warming by using the second LoTD.

These findings show that the PSTs could not have established a relationship between LoTD and EPs regarding energy pollution (Kurtak-Ad \& Demirci, 2012). However, a small number of PSTs stated that some EPs could have been explained with the help of LoTD. It has been determined in different studies in the literature that prospective teachers have difficulties in explaining the LoTD to the events in daily life and explaining these events with related LoTD (Kırtak, 2010; Öztaş, 2005; Tokuya et al., 2004). In contrast, Smith (2001) stated that the cause of many EPs could be explained with the help of LoTD. Besides, the experts who participated in this study stated that entropy changes in the environment cause many EPs. However, an essential part of the PSTs who participated in this study could not make reasoning EPs with entropy and entropy change. This suggests that PSTs do not understand the concept of entropy as mentioned in the literature (Haglund et al., 2016; Sözbilir \& Bennett, 2007; Sreenivasulu \& Subramaniam, 2013; Christensen et al., 2009). It has also been found that entropy is mixed with energy (Battino, 2007; Kulkarni \& Tambade, 2013; Sozbilir, 2002; Sözbilir \& Bennett, 2007; Yeo \& Zandik, 2001).

In summary, the ninth question's situation is a situation where it can be explained by using all the LoTD and the situations in the second and fifth questions together with the second and third LoTD. The zeroth LoTD determines the situations in the eighth and eleventh questions; the first LoTD can explain situations in the first and third questions; situations in the fourth, sixth and tenth questions can be explained by the second LoTD. Furthermore, the situation in the seventh question can be explained by the third LoTD. While answering questions about EPs in this study, PSTs made explanations using concepts such as entropy and energy instead of making explanations using LoTD. This situation is considered as another finding that supports that PSTs do not have sufficient knowledge about LoTD. Similarly, Bain et al. (2014) stated that in different studies conducted in the literature, students have alternative concepts related to thermodynamic issues and have difficulty understanding this subject for various reasons.

\section{CONCLUSION}

When the information about the PSTs' LoTD was examined as a whole, it was found that the PSTs did not have sufficient knowledge about LoTD. This can be explained by the fact that the PSTs have not been able to adopt LoTD during their education or be explained by prejudice against the issues related to LoTD. The PSTs' lack of knowledge about the LoTD is thought to be the main reason underlying their inability to make reasoning LoTD with EPs. Because the PSTs stated that some EPs could be explained with the help of LoTD, they cannot make these explanations at the expected level can be interpreted as another indication that the PSTs do not have enough knowledge about LoTD.

Although it was observed that the PSTs had received LoTD and environmental issues during their undergraduate education, they were found to have difficulty applying any LoTD to a daily event or EPs. At this point, the quality of teaching as a source of information deficiencies should be questioned. While eliminating the deficiencies identified, it is recommended that teaching should be supported with cases and events from daily life, especially EPs. It is believed that preparing and presenting an enriched learning environment during this teaching will strengthen the students' knowledge structures. However, the entropy concept should be well understood, and the relationship between this concept and environmental issues and LoTD should be emphasized.

EPs should be emphasized in 'Environmental Science' courses and should be discussed in connection with ecology issues. Therefore, it will be challenging to achieve the targeted success in environmental education for teachers who are far from EPs, lacking ecological knowledge and culture, not equipped with vast experience and skills, do not have deep knowledge, and cannot be exemplary to children with their behavior.

\section{REFERENCES}

Abraham, M. R., Williamson, V. M., \& Westbrook, S. L. (1994). A crossage study of the understanding of five chemistry concepts. Journal of Research in Science Teaching, 31(2), 147-165. https://doi.org/10.1002/tea.3660310206

Bain, K., Moon, A., Mack, M. R., \& Towns, M. H. (2014). A review of research on the teaching and learning of thermodynamics at the university level. Chemistry Education Research and Practice, 15(3), 320335. https://doi.org/10.1039/C4RP00011K

Baran, M., \& Sözbilir, M. (2018). An application of context-and problem-based learning (C-PBL) into teaching thermodynamics. Research in Science Education, 48(4), 663-689. https://doi.org/10.1007/s11165-016-9583-1

Başer, M., \& Çataloğlu, E. (2005). Effect of conceptual change oriented instruction on remediation of students' misconceptions related to heat and temperature concepts. HU Journal of Education, 29, 43-52. Retrieved from http://www.efdergi.hacettepe.edu.tr/shw_artcl763.html

Battino, R. (2007). "Mysteries" of the first and second laws of thermodynamics. Journal of Chemical Education, 84(5), 753-755. https://doi.org/10.1021/ed084p753

Çalık, M., \& Cobern, W. W. (2017). A cross-cultural study of CKCM efficacy in an undergraduate chemistry classroom. Chemistry Education Research and Practice, 18, 691-730. https://doi.org/10.1039/C7RP00016B

Christensen, W. M., Meltzer, D. E., \& Ogilvie, C. A. (2009). Student ideas regarding entropy and the second law of thermodynamics in an introductory physics course. American Journal of Physics, 77(10), 907-917. https://doi.org/10.1119/1.3167357

Cochran, M. J., \& Heron, P. R. (2006). Development and assessment of research-based tutorials on heat engines and the second law of thermodynamics. American Journal of Physics, 74(8), 734-741. https://doi.org/10.1119/1.2198889

Cohen, L., Manion, L., \& Morrison, K. (2007). Research methods in education (6 $6^{\text {th }}$ edition). New York: Routledge. 
Coștu, B., Ünal, S., \& Ayas, A. (2007). The use of daily-life events in science teaching. Abi Evran University Krrşehir Journal of Education Faculty, 8(1), 197-207. Retrieved from https://dergipark.org.tr/tr/download/article-file/1495944

Cotignola, M. I., Bordogna, C., Punte, G., \& Cappannini, O. M. (2002). Difficulties in learning thermodynamic concepts: Are they linked to the historical development of this field? Science \& Education, 11, 279-291. https://doi.org/10.1023/A:1015205123254

Covitt, A. B., Gunckel, L. K., \& Anderson, W. C. (2009). Students' developing understanding of water in environmental systems. The Journal of Environmental Education, 40(3), 37-51. https://doi.org/10.3200/JOEE.40.3.37-51

Haglund, J., Andersson, S., \& Elmgren, M. (2016). Language aspects of engineering students' view of entropy. Chemistry Education Research and Practice, 17(3), 489-508. https://doi.org/10.1039/C5RP00227C

Harrison, A. G., Grayson, D. J., \& Treagust, D. F. (1999). Investigating a grade 11 student's evolving conceptions of heat and temperature. Journal of Research in Science Teaching, 36(1), 55-78. https://doi.org/10.1002/(SICI)1098-2736(199901)36:1<55::AIDTEA 5 $>3.0$. CO $2-\mathrm{P}$

Kahyaoğlu, M. (2009). Perspectives, readiness and self-efficacy of preservice teachers related to teaching environmental problems in the context of science and technology education. Mebmet Akif Ersoy University Journal of Education Faculty, 9(17), 28- 40.

Kırtak-Ad, V. N., \& Demirci, N. (2012). Prospective teachers' levels of associating environmental problems with science fields and thermodynamics laws. Abi Evran University Kurşsehir Journal of Education Faculty, 13(3), 19-46. Retrieved from https://dergipark.org.tr/tr/download/article-file/1491685

Kurtak, V. N. (2010). Prospective physics, chemistry and biology teachers' levels of associating thermodynamics laws with daily life and environmental problems (Unpublished Master's Thesis). Balıkesir University, Turkey (in Turkish).

Klimenko, A. Y. (2012). Teaching the third law of thermodynamics. The Open Thermodynamics Journal, 6, 1-14. DOI: 10.2174/1874396X01206010001

Kulkarni, V. D., \& Tambade, P. S. (2013). Assessing the conceptual understanding about heat and thermodynamics at undergraduate level. European Journal of Physics Education, 4(2), 9-16. Retrieved from http://www.eu-journal.org/index.php/EJPE/article/view/85

Landis, J. R., \& Koch, G. G. (1977). The measurement of observer agreement for categorical data. Biometrics, 33(1), 159-174. https://doi.org/10.2307/2529310

Loverude, M. E., Kautz, C. H., \& Heron, P. R. L. (2002). Student understanding of the first law of thermodynamics: Relating work to the adiabatic compression of an ideal gas. American Journal of Physics, 70(2), 137-148. https://doi.org/10.1119/1.1417532

Mansson, B. A., \& McGlade, J. M. (1993). Ecology, thermodynamics and H.T. Odum's conjectures. Oecologia, 93, 582-596. https://doi.org/10.1007/BF00328969

Meltzer, D. E. (2007). Investigation of student learning in thermodynamics and implications for instruction in chemistry and engineering. In AIP Conference Proceedings (Vol. 883, No. 1, pp. 3841). American Institute of Physics. https://doi.org/10.1063/1.2508686

Miles, M. B. \& Huberman, A. M. (1994). Qualitative data analysis (2nd edition). California: Sage Publications.

Öztaş, F. (2005). A research towards establishing 9th grade secondary school students' opinions on material cycle and energy flow. Kastamonu Education Journal, 13(2), 381-390.

Patton, M. Q. (1990). Qualitative evaluation and research methods (2nd edition). Thousand Oaks: Sage Publications.

Pidgeon, N., \& Demski, C. C. (2012). From nuclear to renewable: Energy system transformation and public attitudes. Bulletin of the Atomic Scientists, 68(4), 41-51 https://doi.org/10.1177/0096340212451592
Ribeiro, G. T. C. (1992). Entropy and the second principle of thermodynamics-Fourth year undergraduates' ideas. Research in Assessment, 9, 23-36.

Smith, C. (2001). Environmental physics (2nd edition). New York: Routledge.

Sozbilir, M. (2002). Turkish chemistry undergraduate students' misunderstandings of Gibbs free energy. University Chemistry Education, 6(2), 73-83.

Sözbilir, M. (2004). What makes physical chemistry difficult?: Perceptions of Turkish chemistry undergraduates and lecturers. Journal of Chemical Education, 81(4), 573-578. https://doi.org/10.1021/ed081p573

Sözbilir, M., \& Bennett, M. J. (2007). A study of Turkish chemistry undergraduates' understandings of entropy. Journal of Chemical Education, 84(7), 1204-1208. https://doi.org/10.1021/ed084p1204

Sreenivasulu, B., \& Subramaniam, R. (2013). University students' understanding of chemical thermodynamics. International Journal of Science Education, 35(4), 601-635. https://doi.org/10.1080/09500693.2012.683460

Tanel, R. (2006). Investigation of the effects of the cooperative learning method on understanding the second law of thermodynamics and entropy (Unpublished doctoral dissertation). Dokuz Eylul University, Turkey (in Turkish).

Tatar, E., \& Oktay, M. (2011). The effectiveness of problem-based learning on teaching the first law of thermodynamics. Research in Science \& Technological Education, 29(3), 315-332. https://doi.org/10.1080/02635143.2011.599318

Thomas P. L., \& Schwenz R. W. (1998). College physical chemistry students' conceptions of equilibrium and fundamental thermodynamics. Journal of Research in Science Teaching, 35(10), 1151$1160 . \quad$ https://doi.org/10.1002/(SICI)10982736(199812)35:10<1151::AID-TEA6>3.0. CO;2-K

Tokuya, I., Yamamoto, G., \& Takashi, S. (2004). How do students understand and environmental issues in relation to physics. In Y. Park (Ed.), Teaching and Learning of Physics in Cultural Contexts (pp. 165-180). Cheongwon, South Korea: World Scientific Publication. https://doi.org/10.1142/9789812702890_0017

Yaman, F., Ayas, A., \& Çalık, M. (2019). Facilitating grade 11 students' conceptual understanding of fundamental acid-base models. Turkish Journal of Education, 8(1), 16-32. https://doi.org/10.19128/turje.449100

Yeo, S., \& Zandik, M. (2001). Introductory thermal concept evaluation: Assessing students' understanding. The Physics Teacher, 39, 496-504. https://doi.org/10.1119/1.1424603

Yıldırım, A., \& Şimşek, H. (2011). Qualitative research methods in social sciences ( $8^{\text {th }}$ edition). Ankara: Seckin Publishing.

Yin, R. K. (2003). Case study research and applications: Design and methods (3 $3^{\text {rd }}$ edition). Thousand Oaks: Sage publications.

Yücel, S. A., \& Morgil, İ. (1998). Investigation of environmental phenomena in undergraduate education. HU Journal of Education, 14, 84-91. 